\title{
THE USE OF NEW TECHNIQUES IN SPATIAL MODELING AND ANALYSIS OF URBAN QUALITY OF LIFE: MULTIPLE-CRITERIA DECISION ANALYSIS AND GIS
}

\author{
Salim DEHIMI* \\ University of M'sila, Department of Urban Engineering, Laboratory of Urban \\ Technologies and Environment, Algeria, e-mail: salim.dehimi@univ-msila.dz
}

\begin{abstract}
Citation: Dehimi, S. (2021). THE USE OF NEW TECHNIQUES IN SPATIAL MODELING AND ANALYSIS OF URBAN QUALITY OF LIFE: MULTIPLE-CRITERIA DECISION ANALYSIS AND GIS. GeoJournal of Tourism and Geosites, 35(2), 355-363. https://doi.org/10.30892/gtg.35213-659
\end{abstract}

\begin{abstract}
The research aims to analyze and evaluate the quality of urban life using modern technologies by engaging residents and experts to choose criteria for analyzing and evaluating the quality of life (QoL)using multi-criteria analysis and a geographic information system to conduct spatial modeling to extract a Qol analysis and evaluation map and determine its geographical ranges. The study showed that (4.44\%) represent a high QOL and (47.23\%) represent an acceptable QOL and (48.33\%) represent a low QOL. The study proved that there are geographical differences between the city center and the suburbs that can be spatially determined.
\end{abstract}

Key words: quality of life, Delphi method, spatial modeling, GIS, multi-criterion analysis for decision-making, Djelfa

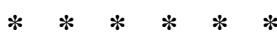

\section{INTRODUCTION}

Due to the rise of Immigration, the rural displacement, and the unchecked development of Algerian cities as a result of Algeria's insecurity and terrorism (Dehimi and Hadjab, 2019), the city of Djelfa was a place of displacement in which inhabitants of the neighboring areas settled. This fact led to rapid and illegal expansion of the city, which caused low level in the quality of life (QoL). Nowadays, cities are in competition to offer the best QoL to their residents. In Britain, in particular, highly educated people showed their readiness to move to places of high QoL across the boundaries of their country and continent (Massam, 2002). Because the QoL has different aspects such as the urban environment, social or commercial facilities, and services (Heydari and Bakhtar, 2018), geographers are trying to understand the complex term by combining different approaches. The first conducted studies on the QoL appeared in the 1960s.

They were basically dealt with from a psychological or an environmental view point. Other works appeared in the 1970s by geographers who studied spatial differences in social indicators (Knox, 1975), but they have roots in the means of economic measurement during the 18th, the 19th and the early 20th centuries (Mostafa, 2012).

In recent times, the use of computational models, tools and indicators has witnessed a sudden increase in assessing QoL at the neighborhood level. AARP livelihood index (AARP-AARP public policy institute, 2018), QoL assessment indicators (Dehimi and Hadjab, 2019) index (intelligence, 2015), livable city index (Onnom et al., 2018) indicator (Mittal et al., 2020) (quality of life index (LQI)) QoL index (Dissanayake et al., 2020) to name but a few. QoL is an interdisciplinary field where sociologists, psychologists, socio-geographers, and economists attempt to assess living conditions objectively and subjectively on the basis of available data, whether objective or subjective (Domin et al., 2010; Merschdorf et al., 2020; Mizgajski et al., 2014; Mittal et al., 2020; Abd el karim and Awawdeh, 2020 ; Garau and Pavan, 2018 ; Mizgajski et al., 2014; Dissanayake et al., 2020) in recent years there has been a lot of interest in the QOL issue in the field of geography however, it is difficult to find an agreed definition or measure it, and the reason for the difference in the approaches and goals of scholars (Ištok and Martin, 2012.) Researchers associate QOL with satisfaction with life (well-being), and QOL is understood as the quality of a place. It is related to the relationship between the person, the place of living and his ability to survive, which indicates aspects of spatial differentiation (Martin and Robert, 2016), of the difficulties is the lack of an agreed definition of QOL, which is a multifaceted problem that has attracted much interest in urban geography (Massam, 2002), each according to their specialization and point of view .Recently, indicators such as the cultural and artistic workforce, diversity of origins, sexual orientation, and residential diversity have been taken into account (Florida, 2002).

The idea behind QoU studies is to measure and evaluate the relationship between social and urban characteristics of a place and perceived QoL (Merschdorf et al., 2020). We believe that this approach is beneficial for establishing a balanced development, as QOL research reveals in terms of spatial disparities and disparities, regional disparities affect inequality between regions, regions, and settlements .Previous researchers have made a number of attempts to define, evaluate, measure, and quantify QoL or well-being within different types of perspectives, including :QOL is an issue that has caught considerable attention in the urban geography because it is difficult to find an agreed-upon definition or to measure it (Massam, 2002). Recently, other indicators have been taken into consideration such as the cultural and artistic workforce, the diversity of origin and the sexual orientations, and housing diversity (Meric et al., 2002). One of the studies that dealt with the QoL is of Petr Kladivo who employed a set of 30 variables expressing the quality of living conditions in the city

\footnotetext{
" Corresponding author
} 
(Kladivo and Halás, 2012). His study focused on social, commercial, and environmental indicators, using multi-variables analysis; and he concluded that the quality of housing, attractiveness of the environment and the availability of services are crucial indicators of the quality of living conditions, according to his respondents. Kladivo involved residents in his analysis, but he did not use programs to determine the areas spatially. The second study was conducted by (Rinner, 2007) who used geographic conceptualization principles GeoVis along with multi-frequent evaluation styles to support spatial decision making. He used AHP to calculate the weights that form the urban QoL, including social, economic, and demographic indicators in the cities. However, he did not involve the residents in his study. Besides, the researcher focused in his interviews with the experts on implementing only GeoVis which did not state clearly the shift from AHP and the spatial ranges of QoL. In his study (Merschdorf et al., 2020), which aims to develop a model for predicting the urban quality of life (QoUL), based on the analysis of objective indicators (economic, social, and environmental), the researcher used his research variables from the previous QoUL. Surveys based on GIS have been experimentally demonstrated to predict service quality. We support this suggestion for these indicators are reliable, as we can see this from the good studies in the QoUL, (Dissanayake et al., 2020). The aim of the research was to develop indicators of QoL.

The researcher used two strategies to determine the first indicators through consultations with experts and administrative authorities in the study area. In the second, the opinions of the residents were observed by conducting formal interviews with the residents of the study area, and we support this idea because the combination of expert opinion and the population supports the research idea and can determine the indicators with all credibility. The researcher also used the multi-criteria decision-making method (MCDM) where the weights of the indicators were determined through the AHP process, and the researcher used geographic information systems to extract the QoL map. The study (Abd El Karim and Awawdeh, 2020) aims to use an innovative approach to assess the quality of the urban environment based on the services provided in terms of distance and time criteria by integrating network analysis based on (GIS) and (MCDA). The researcher identified and selected criteria that affect the quality of urban life in the study area based on local and international literature and personal interviews. We support this option, but the researcher should have involved the local population at this stage of the research.

The researcher used the AHP method in determining the weighting preferences for the evaluation criteria, which is a good method in such type of research, and the results of the research were very satisfactory, as the results of the final suitability map for the definition of the study came. The region revealed five living standards according to the services provided, these results are important for decision-makers in the urban planning process and the process of preparing sustainable urban development plans in order to strengthen the infrastructure according to the needs of the city population.

With the multiplicity of methods and methods for assessing the QoL in our research, we will combine the Delphi method in selecting QOL variables with the participation of the population in selecting indicators that drive Qol research to approach the practice of their lives, and the AHP method for hierarchical analysis in comparing them, extracting the weight of each variable and finally translating all results To the map. The main aim of the research is to use modern techniques in spatial modeling and urban quality analysis by involving local populations and experts.

\section{MATERIALS AND METHODS}

In this study, the Delphi method was applied with a multi-criteria analysis method for decision-making using Geographical Information Systems GIS to develop indicators for measuring the QoL in Djelfa. The study lasted for 3 years, and the analysis was done in three steps. First, the local residents and a group of experts were involved in all stages. Second, modern techniques of hierarchical analysis were used in comparing key factors and sub-factors.

Third, the results were put into QGIS program to come out with a map to identify and evaluate the QoL in the city according to the criteria set by the experts and residents' opinions. The majority of issues associated with the QoL evaluation require methods that can be integrated in GIS, which are powerful tools designed for managing, transforming and representing referenced data spatially (Jones, 2014). The use of GIS enables us to manage and analyze spatially and to model QoL data in the city. GIS techniques and procedures contributed profoundly to decision making being able to analyze a set of spatial data, on one hand (Drobne and Lisec, 2009; Najafifar et al., 2019).

On the other hand, they also contributed to the implementation of effective measures designed to analyze the preferences and assessments expressed by experts and local inhabitants. Therefore, the ultimate goal of using GIS is to provide support for spatial decisions, while multi-criteria decision-making procedures determine the relationship between "input" and "output" maps (Drobne and Lisec, 2009). Figure 1 summarizes the methodology used in this paper.

\section{RESULTS AND DISCUSSION}

\section{Delphi Method}

In selecting the QoL factors in the city, Delphi method was used as an organized technique of communication (Sackman, 1974). It can be defined as "a systematic and interactive method of prediction" that relies on a committee of experts" (Norman and Olaf, 1963). Therefore, this method is "for interactive decision-making based on the term collective intelligence of experts." (Rowe and Wright, 2001). Experts are required to answer questionnaires in "two or more stages" for accurate judgments (Turoff and Scher, 2002; Lund, 2020). After each stage, the researcher submits an anonymous summary containing a summary of experts' expectations from the previous stage and the base on which they made their judgments (Harold et al., 2002). Experts are encouraged to review their previous responses in the light of responses from different persons of the Committee of experts, and it is certain that through this process, the scope of responses will be reduced and the group of experts' views would cluster towards the "correct" answer. At the end, the procedure would be stopped at the predetermined "stop criterion" and the averages of the final stage's degrees determine the results (Qureshi et 
al., 2014). In this study, we worked on four phases with a group of 30 experts from different disciplines, namely: environment, urbanization, economics, and sociology (including professors, colleagues at work, engineers in private companies and public entities, associations' managers, decision makers, public and private institutions managers, and social activists) to establish different and varied criteria based on opinions of the majority. The main questions sent to experts included: what were the suggested variables to assess the QoL in the city of Djelfa? And how are they measure?

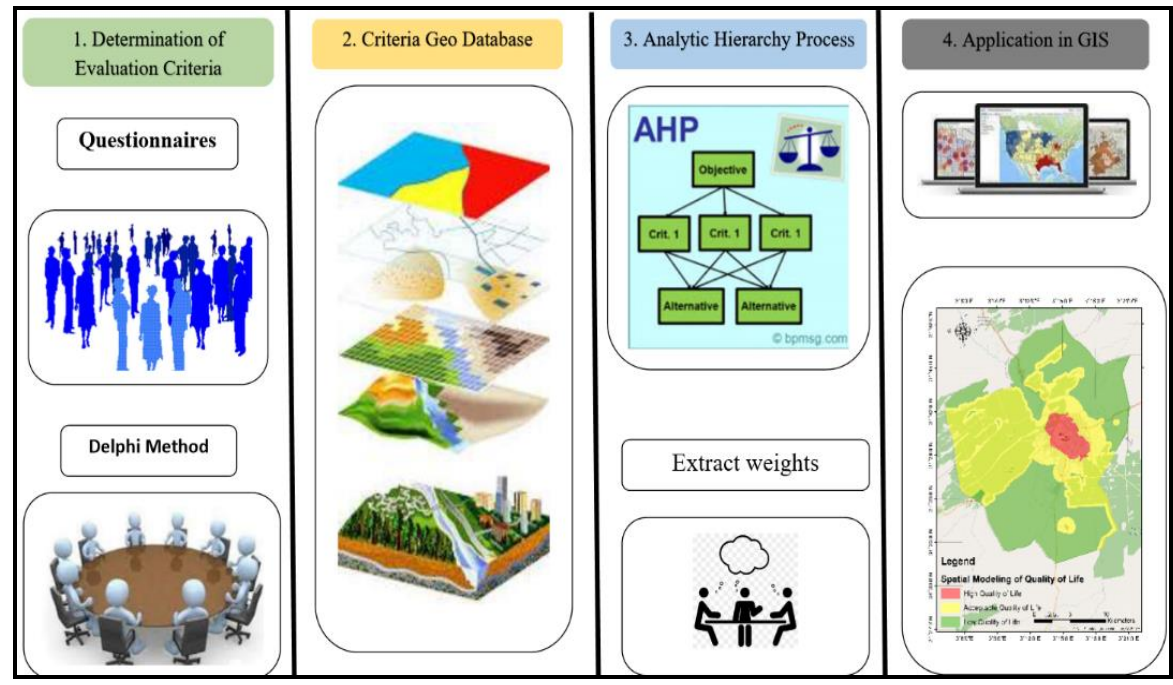

Figure 1. Analysis procedure used in this paper

In every stage of the above four stages, expert expectations were resent back for re-evaluation using Likert scale (Allen and Seaman, 2007). Then, six variables were put, namely health, social services, education, environment, culture and entertainment, security, and protection. Finally, experts proposed three service area indicators for all variables to be measured spatially, including a "benefited from the service", "partly benefited", and "not benefited". In the second stage after collecting the variables, questionnaires were handed out to the inhabitants of the city. The sample of inhabitants was randomly selected and answers were collected immediately.

384 enclosed questionnaires were distributed to evaluate the QoL in the city according to the mentioned factors. 381 questionnaires were received and 3 ones were either lost or sent back blank. Among the questions asked in the questionnaire were: Among the suggested variables, what is the most necessary service for you? What is the convenient distance between home and the services? Do these variables contribute in the welfare of the city residents? What is relationship between distance and service quality? Beside these questions, the degree of preference between the various principal and subsidiary criteria was examined according to the residents' opinion using Thomas Saaty scale Table 1 to compare variables and to take opinions of the majority of residents in AHP comparison.

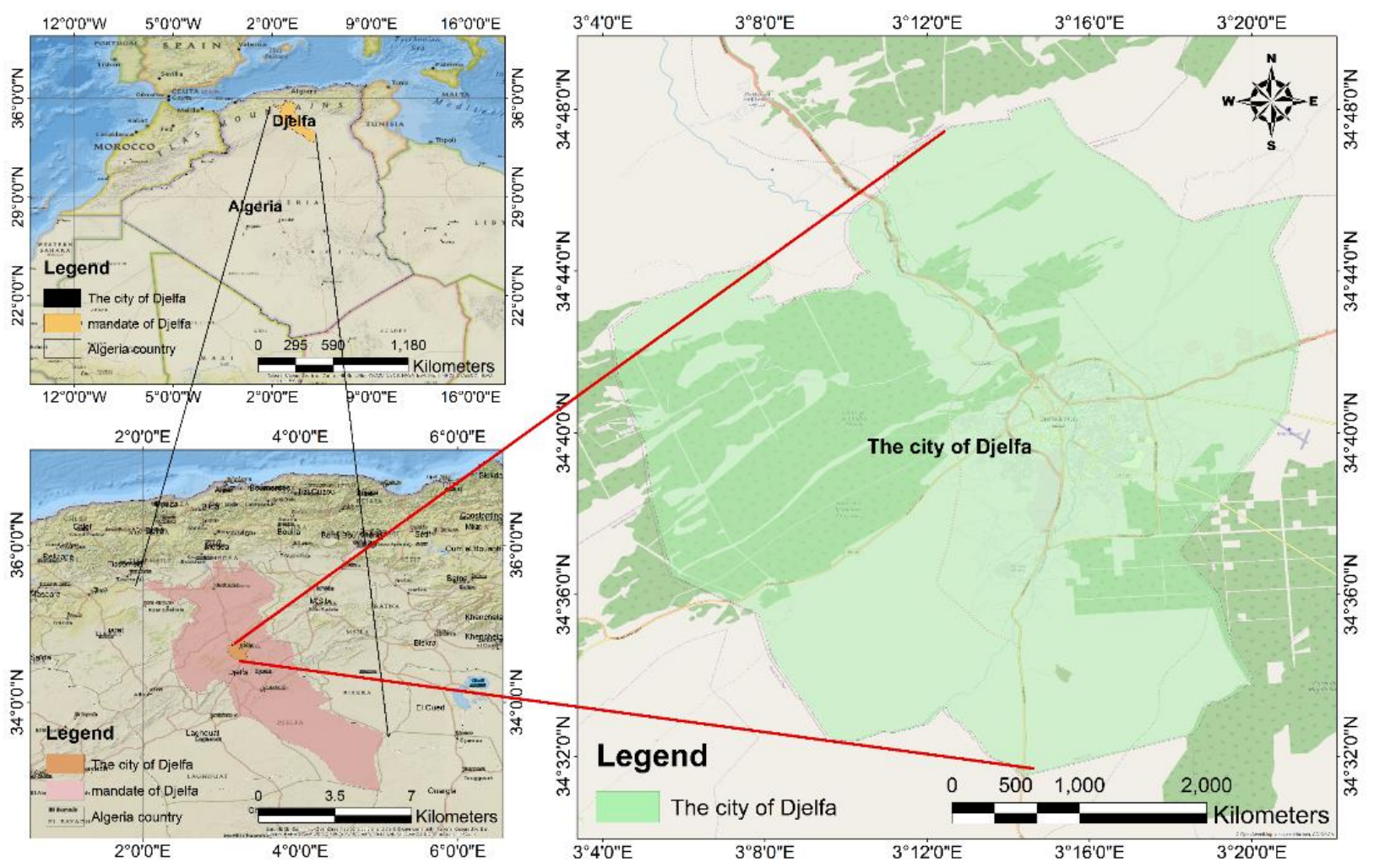

Figure 2. Location of the study area in Djelfa city

\section{STUDY AREA}

Djelfa is an internal Algerian city located within the following geographical coordinates: between the latitudes ( $34.32^{\circ}$ and $\left.34.48^{\circ}\right)$ north of the equator and between longitudes $\left(3.4^{\circ}\right.$ and $\left.3.20^{\circ}\right)$ east of the Greenwich Meridian. The municipality of 
Djelfa is the main residential community in the area of study. It occupies an area of $527.91 \mathrm{~km}^{2}$ with population of 332968 inhabitants. The population density is about 631 people / $\mathrm{km}^{2}$, according to the Municipal Statistics Office (2015) and Statistics (2015). The study area of the urban region in the city is estimated at 527, $91 \mathrm{~km} 2$ as in shown in Figure 2

Variables for evaluating the QoL in the city: As stated earlier, parameters were defined using the Delphi system to measure the QoL by applying a multi-criterion analysis through the objective hierarchy process to decision-making (Çağliyan and Ayhan, 2019; Kamali et al., 2017). Spatial analysis was conducted using the function Spatial analysis: distance analysis Euclidean distance (Raghunath, 2006) after the compilation of geographical data for each element of the six variables, then reclassified according to predetermined distances.

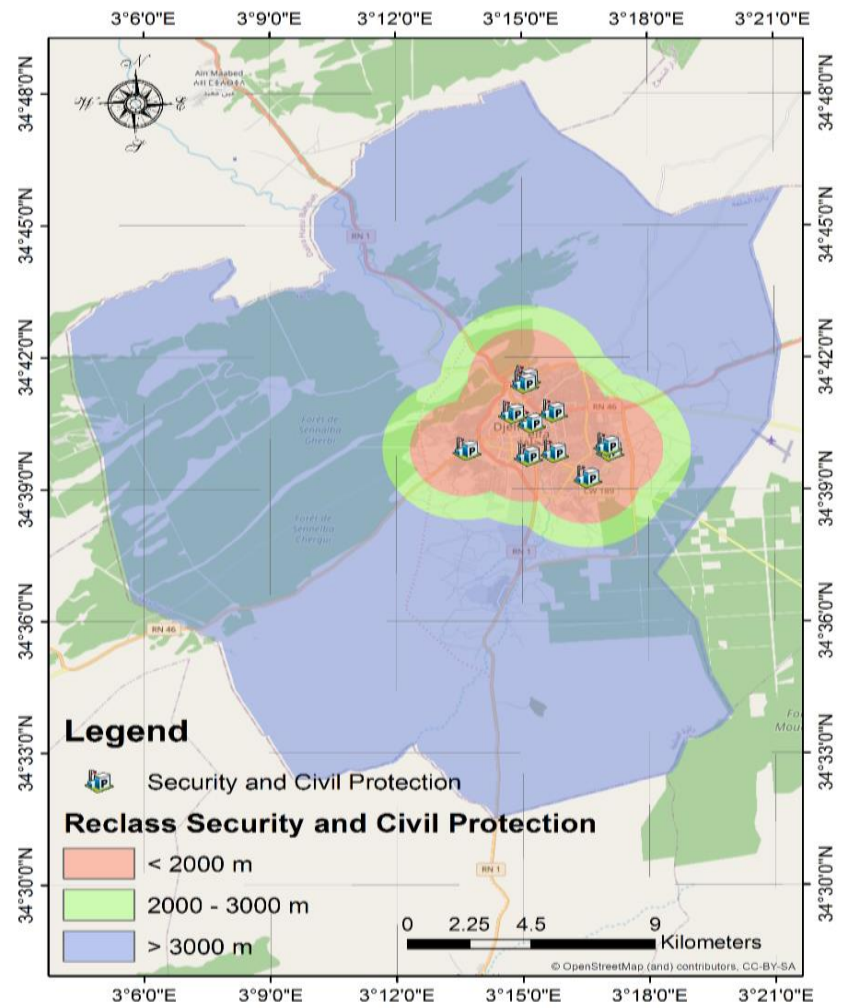

Figure 3. Security and Civil Protection

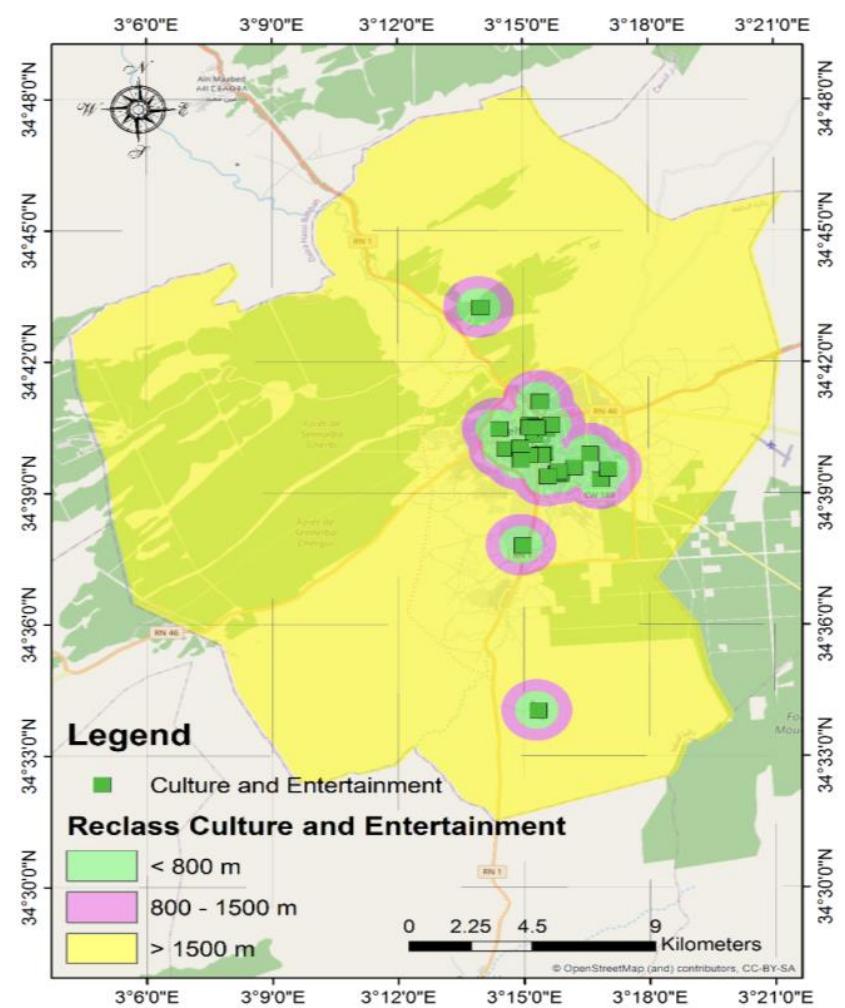

Figure 5. Culture and Entertainment

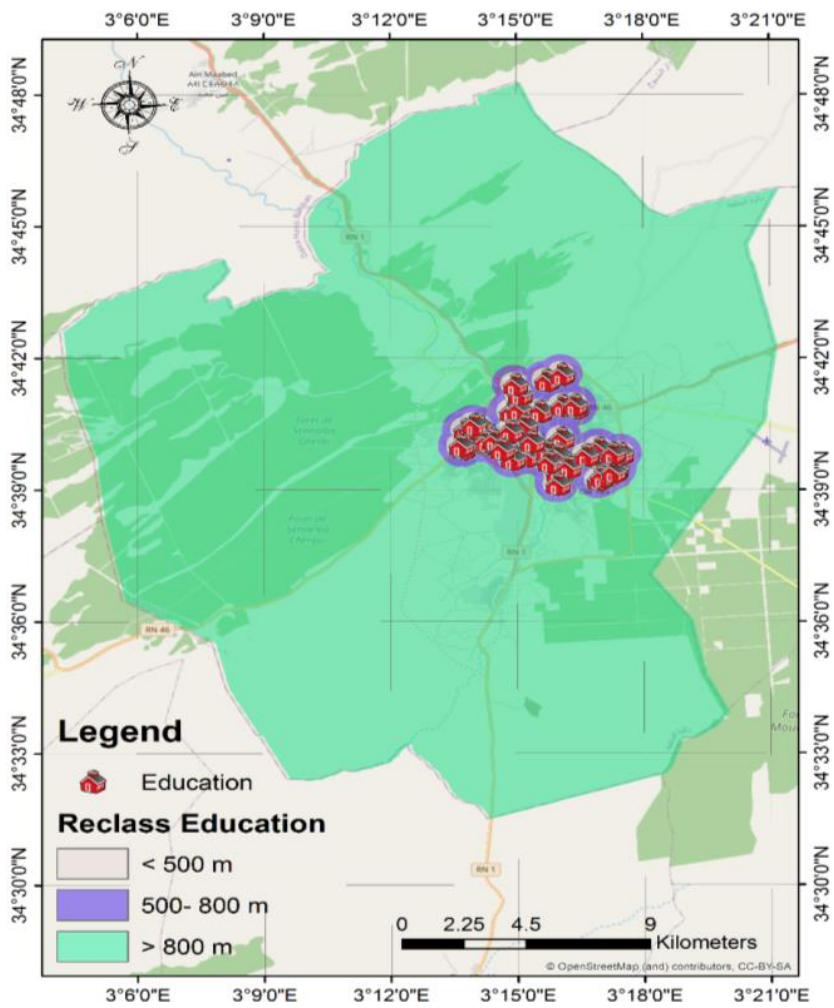

Figure 4. Education

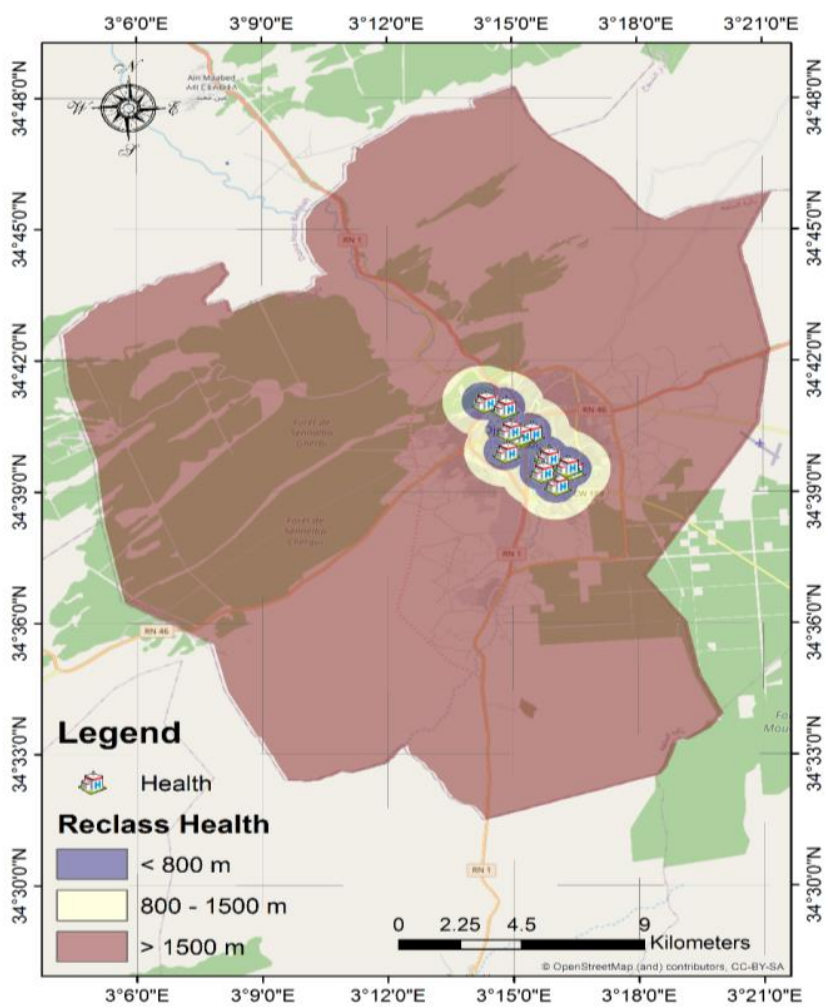

Figure 6. Health 
Security and Civil Protection: Information was obtained in this variable by field surveys and the identification of all police stations and fire departments and the establishment of a layer for the latter in the GIS application. Based on the views of experts and field surveys, police stations and fire departments were selected to assess the ranges of service: (less than $1500 \mathrm{~m}) ;(1500 \mathrm{~m}$ to $2000 \mathrm{~m})$; (more than $2000 \mathrm{~m})$, Figure 3.

Education: I contacted the Education Directorate in Djelfa to collect spatial and descriptive data. For the ranges of service, the experts determined: (less than $500 \mathrm{~m}$ ); (500 m to $800 \mathrm{~m}$ ); (more than $800 \mathrm{~m}$ ), as indicated in Figure 4.

Culture and Entertainment: In this variable, we focused on all entertainment centers, including public parks, recreation centers, football fields, swimming pools, theater houses, movie theaters, community centers, cultural centers, and all social-related centers. The scope of operation was based on expert views, but the data were gathered from the Youth and Sports Directorate and the Djelfa Culture Directorate. Service ranges were defined as follows: (less than $600 \mathrm{~m})$; (600 m to $800 \mathrm{~m}$ ); (more than $800 \mathrm{~m}$ ), as indicated in Figure 5.

Health: In this variable, information was collected on the basis of Djelfa the design of the planning and remodeling of Djelfa with field examination to renew the gathered information. A layer was then established for all health centers and hospitals. The ranges of service were determined by the experts' opinions as follows: (less than $700 \mathrm{~m})$; (700 m to $900 \mathrm{~m})$; (more than $900 \mathrm{~m}$ ), as shown in Figure 6.

Public Services: In this variable, we relied on all necessary public services distributed along the city, including post offices, municipal branches, telephone service offices, water supply service, religious facilities, besides the urban deport service. Data were gathered from the design of planning and reconstruction of Djelfa by 2012 with an examination to update data. The ranges of service were resolved by scholars as: (fewer than $500 \mathrm{~m}$ ); (500 m to $800 \mathrm{~m}$ ); (more than $800 \mathrm{~m}$ ), Figure 7.

Environment: Green areas, fields, orchards, forests, water basins, arid areas and green areas were identified and classified through field surveys and satellite images. Experts exclude service areas as in previous variants and area-specific classifications only, as indicated in Figure 8.
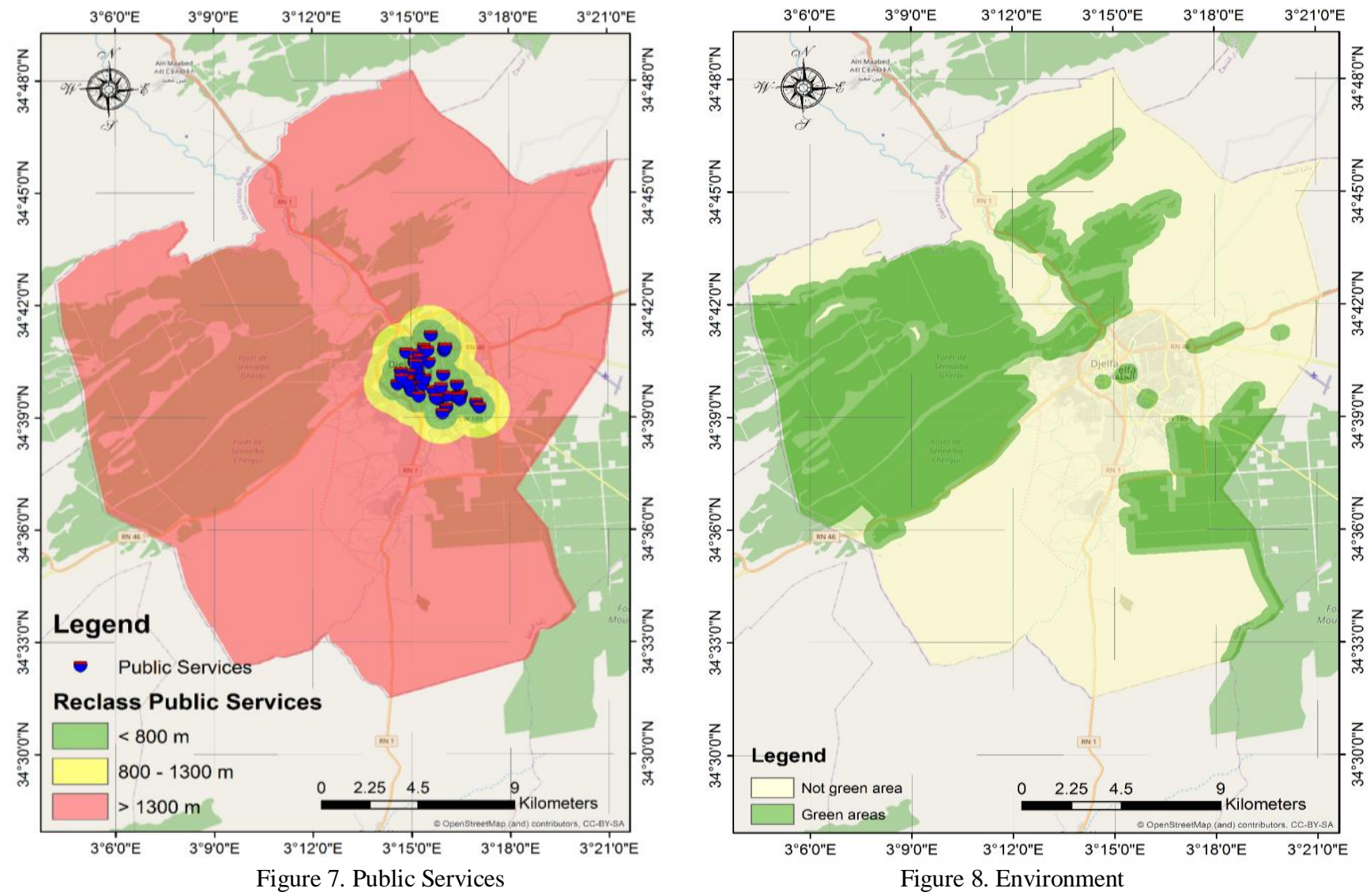

From the maps above, it can be noted that the study area, from the maps mentioned above, is full of educational services; however, the environment variable is not available because the city does not have green spaces, only some fruit tree fields. All health, cultural and recreational services are concentrated in the city center. Other services throughout the city.

Analytic Hierarchy Process: In the 1980s, Thomas Saaty developed a method of analytical hierarchy process AHP (Dadras et al., 2014; Dissanayake et al., 2020). This process paved the way to include provisions concerning intangible quality criteria by concrete quantitative criteria (Badri, 2001). It is a quantitative method for evaluating and ranking the alternatives for a given target (Cheah et al., 2018). For Saaty, it is "an integrated framework that combines substantive and non-substantive criteria," based on a pairwise comparison and relative scale (Saaty, 1980). AHP is a powerful and flexible technique which formulates the problem in pyramid structure, it combines the qualitative and quantitative aspects of a decision and provides a simple method for assessing selection criteria, thus minimizing bias in decision-making (Ma et al., 2005; Abd El Karim and 
Awawdeh, 2020). It also describes a map-focused interactive application to support spatial decision (Rinner, 2007). At the end of the process, the weights of the main evaluation criteria are produced. Application of analytic hierarchy process: After creating a database of all variables and doing a spatial analysis, analytic hierarchy process comes to extract the weights and the primary and secondary variables. The procedure is summarized in the following steps:

Analysis: A complex problem breaks down in a hierarchy of consistent decision elements. A hierarchical structure is created for the coherence and sequence of all decision elements in the top-down hierarchy (Chalermchai and Nitin, 2008). The target is placed at the top of the hierarchical structure. The lower level of the hierarchical structure consists of more detailed elements, which are related to the criteria at the next higher level (Saaty, 1990).

Prioritization: After the hierarchical structure is created, the relative importance of all elements of decision is captured and detected through pairwise comparisons, which are used to create a ratio matrix. Pairwise comparisons between key criteria and sub-criteria are determined within the same hierarchical level (Boulomytis et al., 2017). The numerical scale was used as suggested by Saaty (Ouma and Tateishi, 2014), ranging from (1 to 9), (Duc, 2006) in the pairwise comparisons of matrices (Saaty, 2008). The results were based on the questionnaires in the comparison between primary and secondary criteria to give them more credibility and impartiality in decisions about preferences. The degrees of the questionnaire were applied to each of these elements according to the degree of importance for Saaty in matrices to be translated into weights (Hosseinali, 2008). Pairwise comparison is made between the key criteria then between the sub-criteria of the same level (Al-shabeeb, 2016). Finally, the weights are extracted. The consistency ratio value CR $=0,05$ was less than 0.1 of Saaty's values in the first hierarchy level AHP process Which means that the distribution of weights between factors is very acceptable (Wei et al., 2011).

Table 1. Reference scale by Saaty (Source: Saaty, 2008)

\begin{tabular}{|c|l|}
\hline Value & Preference Level Numeric \\
\hline $\mathbf{1}$ & Equal Preference \\
\hline $\mathbf{3}$ & Moderate Preference \\
\hline $\mathbf{5}$ & Strong Preference \\
\hline $\mathbf{7}$ & Very Strong Preference \\
\hline $\mathbf{9}$ & Absolute Preference \\
\hline $\mathbf{2 , 4 , 6 , 8}$ & Intermediate Values Between Them \\
\hline
\end{tabular}

Table 2. Comparing AHP among Key Criteria (Source: author's composition)

\begin{tabular}{|l|c|c|c|c|c|c|c|c|}
\hline & Security & Education & Culture & Health & Public & Environment & Weights & Rank \\
\hline Security & 1 & 2 & 2 & $1 / 2$ & 1 & $1 / 2$ & 0,151 & 3 \\
\hline Education & $1 / 2$ & 1 & 1 & $1 / 2$ & 3 & $1 / 2$ & 0,135 & 4 \\
\hline Culture & $1 / 2$ & 1 & 1 & $1 / 5$ & 1 & $1 / 3$ & 0,084 & 6 \\
\hline Health & 2 & 2 & 5 & 1 & 2 & 1 & 0,273 & 1 \\
\hline Public & 1 & $1 / 3$ & 1 & $1 / 2$ & 1 & $1 / 3$ & 0,095 & 5 \\
\hline Environment & 2 & 2 & 3 & 2 & 3 & 1 & 0,261 & 2 \\
\hline \multicolumn{8}{|c|}{ Imax $=6,294 \quad$ CI $=0,059$} & RC I $=1,24 \quad$ cr $=5 \%$ \\
\hline
\end{tabular}

\section{RESULTS AND DISCUSSION}

Multi-criteria spatial analysis requires data related to criteria values and its geographical location in the process of multicriteria spatial decision-based GIS. GIS technology provides access to data storage and retrieval, processing and analyzing data to develop information that can support decisions. In addition to that, the use of GIS in spatial data models provides a system and method for entering and displaying spatial data and spatial analysis tools. For the analytic hierarchy process, results summarize the output AHP program. The pairwise comparison begins from the middle level to the lowest level. The criteria are compared in pairs based on efficiency and according to the higher-level criteria (Albayrak and Yasemin, 2004). Multiple pairwise comparisons in AHP are based on a nine-level standardized comparison scale Table 1.

Supposing $\mathbf{C}=\{\mathbf{C} \mathbf{j} / \mathbf{j}=\mathbf{1}, \mathbf{2}, \ldots, \mathbf{n}\}$ is the set of criteria, the consequence of the pairwise comparison on criteria can be shortened in an $(n \times n)$ evaluation matrix Eq. (1) wherein each element $\left(a_{i j}=1,2 \ldots n\right)$ is the part of criteria weights.

$$
A=\left[\begin{array}{cccc}
a_{11} & a_{12} & \cdots & a_{1 n} \\
a_{21} & a_{22} & \cdots & a_{2 n} \\
\vdots & \vdots & \ddots & \vdots \\
a_{n 1} & a_{n 2} & \cdots & a_{n n}
\end{array}\right], a_{i i}=1, a_{j i}=\frac{1}{s_{i j}}, a_{i j} \neq 0
$$

Finally, normalization is based on the mathematical procedure and that for each matrix there are relative weights. The right eigenvector $(\mathrm{W})$ gives the relative weights corresponding to the biggest eigenvalue, $\left(\lambda_{\max }\right)$ as in Eq. (2):

$$
\mathrm{A}_{\mathrm{W}}=\lambda_{\max } \mathrm{W} \text { Eq. (2) ....(Lotfi et al., 2009) }
$$

As long as the pairwise comparisons are totally consistent, the matrix "A" has rank 1 and $\lambda_{\max }=\mathrm{n}$. Therefore, through normalizing any of the rows or columns, weights can be attained.

Hence, the quality of AHP results is related to the consistency of pairwise comparison judgments. The consistency is defined by the relation between the admissions of: $\mathrm{A}: \mathrm{a}_{\mathrm{ij}} \times \mathrm{a}_{\mathrm{jk}}=\mathrm{a}_{\mathrm{ik}}$. Accordingly, the consistency index (CI) is Eq. (3):

$$
\mathrm{CI}=\left(\lambda_{\max }-\mathrm{n}\right) /(\mathrm{n}-1) \quad \text { Eq. (3) ... (Abd El Karim and Awawdeh, 2020) }
$$

The consistency ratio (CR) is calculated as the ratio of the (CI) divided by the random index (RI), as shown Eq. (4) (Dadras et al., 2014).

$$
\mathrm{CR}=\mathrm{CI} / \mathrm{RI} \text { Eq. (4) ...(Abd El Karim and Awawdeh, 2020) }
$$

For Saaty, if the ratio exceeds 0.1, the set of judgments might not be consistent and cannot be reliable. Therefore, a CR under 0.1 or $10 \%$ is acceptable, but the procedure is repeated if the CR evaluation is inconsistent (Saaty, 2008).

Then, we extracted the measures. The consistency Ratio $(C R=0.05)$ was less than $(0.1)$ of the values of Saaty (Shokati and Feizizadeh, 2019) at the first hierarchical level of AHP, which meant that weight distribution between factors was acceptable and showed good consistency (Ishizaka and Labib, 2009). While comparing the key criteria based on the residents' opinions and using AHP, results of the preferences show that city residents give health care services a priority by 
$27.3 \%$, and green spaces and for relaxation by $26.1 \%$, security and protection comes in third place in terms of priority by $15.10 \%$. Residents believe that security of the city is fundamental to QoL. Educational services came in the fourth place by $13.50 \%$, public services came in fifth place by $9.50 \%$, and then culture and entertainment by $8.40 \%$ of AHP. The results of criteria pairwise comparison Table 2 indicate that residents get to all the services on foot.

In AHP, health occupied the highest percentage, and this suggests that the residents give great importance to health services as well as green spaces, security, and educational services, respectively. After completing the maps of services for all variables and extracting the weights of AHP in QGIS program Because Gis is now within the reach of all users of spatial analysis, Raster Calculator tool is used for spatial analysis deriving the classifications of the QoL based on AHP results. According to experts, ranges should be classified into three areas to be easily read: high, acceptable, and low QoL.

In addition, the tool is used to identify the borders, the areas, and the positions geographically to be useful for decision makers. Before classification, the results of the map Figure 9 show that high QoL is concentrated in the City Center because it has all the services and meets all the needs of the residents.
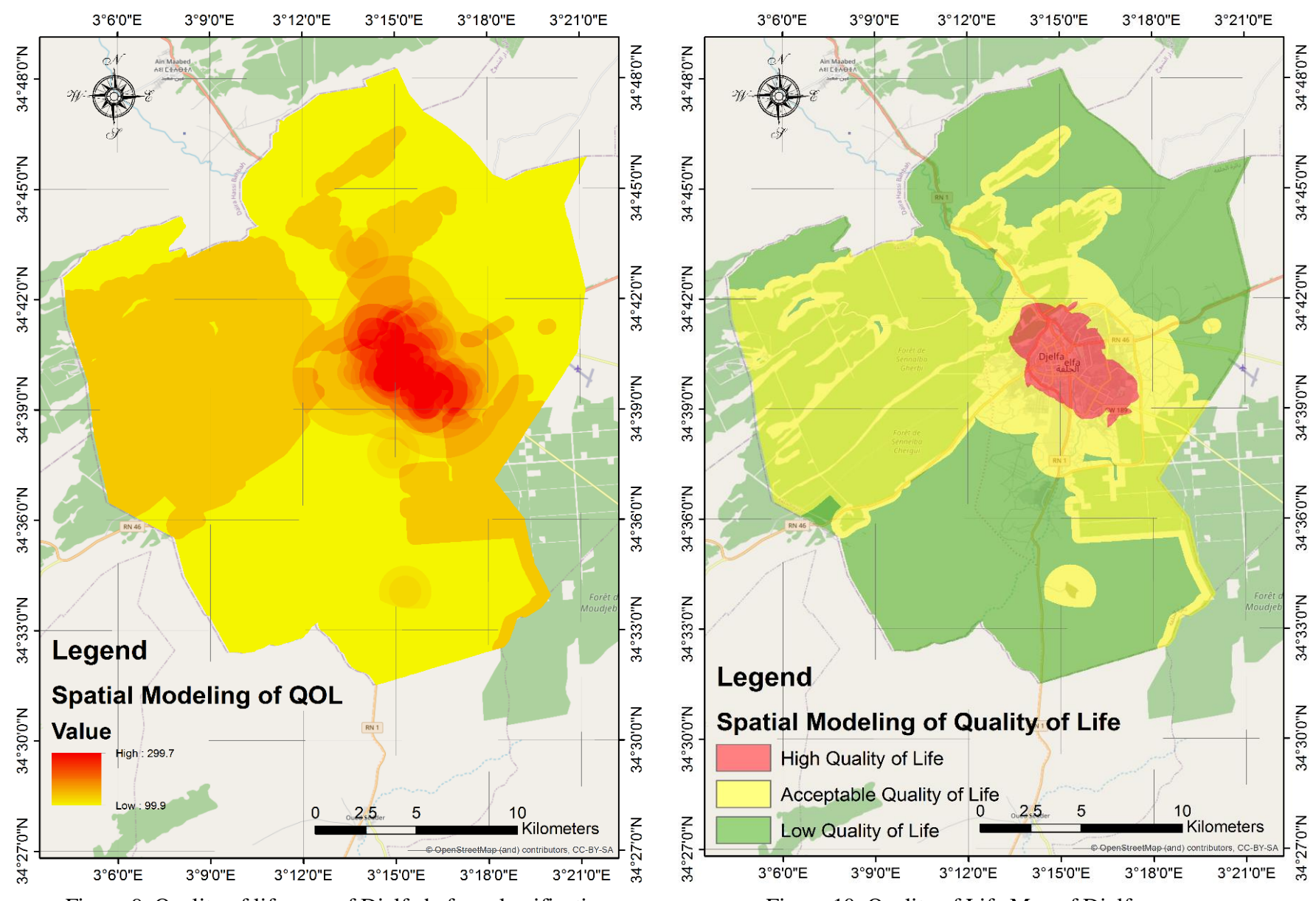

Figure 9. Quality of life map of Djelfa before classification

Figure 10. Quality of Life Map of Djelfa

The results describe the application of Delphi method and AHP in GIS for the purpose of evaluating the QoL in Djelfa city. Evidently, decision support tools integrated in GIS help us explore a variety of reasons and perspectives in evaluating the QoL in the city. The available tools are important for decision makers to solve spatial problems. After converting the QoL map from Raster to Shape file in its triple classification Figure 10, each classification has been calculated.

The results are summarized in the Table 4. By reading the QoL map, it is noted that areas of high life quality according to AHP analysis are at the City Center and the surrounding areas. That is, there is a differentiation in the distribution of services and facilities between the neighborhoods of the city. In this paper, results show that applications of decision making in GIS are multifunctional. They integrate diverse stages in complicating the problem of decision.

Accordingly, the choice of weights and AHP techniques played a central role. It is obvious that decision makers, who prefer a subjective scale, may not come to identical weights for the criteria; which in turn may lead to different results and affect the final decision. In this regard, Drobne states, "the presented methods are only tools to aid decision makers; they are not the decision itself' (Drobne and Lisec, 2009).

Table 3. Random indices from (Source: Saaty, 2008)

\begin{tabular}{|c|c|c|c|c|c|c|c|c|}
\hline $\mathrm{n}$ & 3 & 4 & 5 & 6 & 7 & 8 & 9 & 10 \\
\hline $\mathrm{RI}$ & 0.58 & 0.9 & 1.12 & 1.24 & 1.32 & 1.41 & 1.45 & 1.49 \\
\hline
\end{tabular}

Table 4. Percentage of AHP scale of quality of he life in the city of Djelfa (Source: author)

\begin{tabular}{|c|l|c|c|}
\hline & Classes & Area sq. km. & $\%$ \\
\hline 1 & High Quality of Life & 23,42 & $4,44 \%$ \\
\hline 2 & Acceptable Quality of Life & 249,43 & $47,23 \%$ \\
\hline 3 & Low Quality of Life & 255,24 & $48,33 \%$ \\
\hline
\end{tabular}




\section{CONCLUSIONS}

In this paper, a practical scientific method for modeling and analyzing urban quality of life in developing countries is proposed by combining the Delphi approach with AHP and GIS techniques. Djelfa was selected as a case study for this research. A Delphi-based survey was conducted by a group of experts to come up with a set of criteria for modeling and analyzing QoL in cities. AHP was used to extract weights of the QoL analysis criteria.

The consistency ratio (0.05) was less than $(<0.1)$, and therefore acceptable. After creating a geographical database of the predetermined criteria, the weights derived from the AHP were used in a GIS environment in spatial analysis to extract the QoL map in the city with three classifications: high, acceptable, and low. The results from the map of the area of the study were $(4.44 \%)$ demonstrating a high QoL in the city center with an area of $\left(23.24 \mathrm{~km}^{2}\right)$, and $(47.23 \%)$ representing an acceptable QoL in the city center surrounding areas with an area of $\left(249.43 \mathrm{~m}^{2}\right)$, and $(48.33 \%)$ achieving a low QoL, in the places far from the city center and lucking the necessary services and infrastructure, with an area of $\left(255.24 \mathrm{~km}^{2}\right)$. Here, the geographical differences between the city center and the suburbs are evident. This creates differentiation and social anomalies between them and encourages people to live in the city center.

The participation of the inhabitants and the integration of Delphi's technique with a multi-criteria analysis through the hierarchical analysis in the GIS environment are effective methods because they reflect the actual realities of the residents and translate the results in the form of a map based on scientific foundations and on the cultural aspirations of the community in the evaluation of the QoL. These methods also identify the areas requiring urban development, through creating geographic database to calculate the shortage in services in the city and proposing services in accordance with the study variables.

This method identified high and low QoL regions. Factors remain local and vary by region. The map results can be used to analyze access to key services, identify areas in need of development, suitable places to live, and determine spatial inequalities between neighborhoods. They can be helpful for decision makers in balancing and developing local neighborhoods.

\section{REFERENCES}

Abd El Karim, A., \& Awawdeh, M.M. (2020). Integrating GIS Accessibility and Location-Allocation Models with Multicriteria Decision Analysis for Evaluating Quality of Life in Buraidah City, KSA. Sustainability, 12(04), 1412. https://doi.org/10.3390/su12041412

Albayrak, E., \& Yasemin, C.E. (2004). Using analytic hierarchy process (AHP) to improve human performance: An application of multiple criteria decision-making problem. Journal of Intelligent Manufacturing, 15(4), 491-503. https://doi.org/10.1023/B:JIMS.0000034112.00652.4c

Allen, I.E., \& Seaman, C.A. (2007). Likert scales and data analyses. Quality progress, 40(7), 64-65. http://rube.asq.org/qualityprogress/2007/07/statistics/likert-scales-and-data-analyses.html

Al-shabeeb, A.R. (2016). The Use of AHP within GIS in Selecting Potential Sites for Water Harvesting Sites in the Azraq Basin-Jordan. Journal of Geographic Information System, 8(1), 73. https://doi.org/10.4236/jgis.2016.81008

Badri, M.A. (2001). A combined AHP-GP model for quality control systems. International Journal of Production Economics, 72(1), 27-40. https://doi.org/10.1016/S0925-5273(00)00077-3

Boulomytis, V.T., Zuffo, A.C., \& Imteaz, M.A. (2017). Hydrological Impacts of Urban Developments: Modelling and Decision-Making Concepts. Theoretical and Empirical Researches in Urban Management (4), 5-19. http://www.jstor.org/stable/26234011

Çağliyan, A., \& Ayhan, G. (2019). Geographical Analysis of Summer Houses By the Lake Hazar in Terms of Their Location of Construction (Province of Elaziğ-Turkey). GeoJournal of Tourism and Geosites, 25(2), 648-663. https://doi.org/10.30892/gtg.25229-387

Chalermchai, P., \& Nitin, K.T. (2008). Analytical Hierarchical Process (AHP)-Based Flood Water Retention Planning in Thailand. GIScience \& Remote Sensing, 45(3), 343-355. https://doi.org/10.2747/1548-1603.45.3.343

Cheah, J.H., Memon, M.A., Chuah, F., Ting, H., \& Ramayah, T. (2018). Assessing reflective models in marketing research: A comparison between pls and plsc estimates. International Journal of Business and Society, 19(1), 139-160. http://www.ijbs.unimas.my/ images/repository/pdf/Vol19-no1-paper10.pdf

Dadras, M., Shafri, H.Z., Ahmad, N., Pradhan, B., \& Safarpour, S. (2014). A combined FUZZY MCDM approach for identifying the suitable lands for urban development: an example from Bandar Abbas, Iran. Journal of Urban and Environmental Engineering, 8(1), 11-27. https://doi.org/10.4090/juee.2014.v8n1.011027

Dehimi, S., \& Hadjab, M. (2019). Evaluating the quality of life in urban area by using the Delphi Method . A case study of M'Sila City/Algeria. Romanian Journal of Geography, 2(63), 193-202. http://www.rjgeo.ro/atasuri/revue_roumaine_63_2/dehimi,\%20hadjeb.pdf

Dissanayake, D.M., Morimoto, T., Murayama, Y., Ranagalage, M., \& Perera, E.N. (2020). Analysis of life quality in a tropical mountain city using a multi-criteria geospatial technique: A case study of Kandy City, Sri Lanka. Sustainability, 12(7), 2918. https://doi.org/10.3390/su12072918

Domin, D., Kwiatkowski, G., \& Chodkowska-Miszczuk, J. (2010). Evaluating the Parsęta basin communes' tourist space using the selected quantification methods. Quaestiones Geographicae, 29(3), 21-26. https://doi.org/10.2478/v10117-010-0019-0

Drobne, S., \& Lisec, A. (2009). Multi-attribute decision analysis in GIS weighted linear combination and ordered weighted averaging. Informatica, 33(4), 459-474. http://www.informatica.si/index.php/informatica/article/download/263/260

Duc, T.T. (2006). Using GIS and AHP technique for land-use suitability analysis. In International symposium on geoinformatics for spatial infrastructure development in earth and allied sciences, 1-6.

Florida, R. (2002). The economic geography of talent. Annals of the Association of American geographers, 92(4), 743-755. https://doi.org/10.1111/1467-8306.00314

Garau, C., \& Pavan, V.M. (2018). Evaluating Urban Quality: Indicators and Assessment Tools for Smart Sustainable Cities. Sustainability, 10(3), 575. https://doi.org/10.3390/su10030575

Harold, A.L., Murray, T., \& Olaf, H. (2002). The Delphi Method Techniques and Applications, Addison-Wesley Publishing Company, Advanced Book Program, USA. http://repository.umpwr.ac.id:8080/bitstream/handle/123456789/162/Delphi\%20Method\%20-\%20 Techniques\%20and\%20Applications.pdf?sequence=1

Heydari, A., \& Bakhtar, S. (2018). Analyzing the Regional Development of Kurdish Border Cities of Iran Using Sustainable Urban Development Indices (Study Area: Kurdistan Province). GeoJournal of Tourism and Geosites, 23(3), 797-807. https://doi.org/10.30892/gtg.23315-329 
Hosseinali, F.A. (2008). Weighting spatial information in GIS for copper mining exploration. American Journal of Applied Sciences, 5(9), 1187-1198. https://doi.org/10.1057/ori.2009.10

Ishizaka, A., \& Labib, A. (2009). Analytic hierarchy process and expert choice: Benefits and limitations. Or Insight, 22(4), 201-220. https://doi.org/10.1057/ori.2009.10

Ištok, R., \& Martin, A. (2012). Vybrané Teoreticko-Metodologické Aspekty Výskumu Kvality Života S Prihliadnutím Na Prihraničné Regióny [Selected Theoretical and Methodological Aspects of The Research of the Life Quality in the Border]. Folia Geographica, 80, 54-20.

Jones, C.B. (2014). Geographical information systems and computer cartography. Routledge, Taylor \& Francis Group, London and New York.

Kamali, M., Alesheikh, A.A., Borazjani, S.A., Jahanshahi, A., Khodaparast, Z., \& Khalaj, M. (2017). Delphi-AHP and Weighted Index Overlay-GIS Approaches for Industrial Site Selection Case Study: Large Extractive Industrial Units in Iran. Journal of Settlements and Spatial Planning, 8(2), 99-105. https://doi.org/10.24193/JSSP.2017.2.03

Kladivo, P., \& Halás, M. (2012). Quality of life in an urban environment: A typology of urban units of Olomouc. Quaestiones Geographicae, 32(2), 49-60. https://doi.org/10.2478/v10117-012-0018-4

Knox, P.L. (1975). Social well-being: A spatial perspective. London: Oxford University Press.

Lotfi, S., Habibi, K., \& Koohsari, M.J. (2009). An analysis of urban land development using multi criteria decision model and geographical information system (a case study of Babolsar city). American Journal of Environmental Sciences, 5(1), 87-93.

Lund, B. (2020). Review of the Delphi method in library and information science research. Journal of Documentation, 76(4), 929-960. https://doi.org/10.1108/JD-09-2019-0178

Ma, J., Scott, N.R., DeGloria, S.D., \& Lembo, A.J. (2005). Siting analysis of farm-based centralized anaerobic digester systems for distributed generation using GIS. Biomass and Bioenergy, 28(6), 591-600. https://doi.org/10.1016/j.biombioe.2004.12.003

Martin, A., \& Robert, I. (2016). How to assess quality of life. Theoretical and methodological research aspects in cross-border regions. Folia Geographica, 32(32), 19-32. https://doi.org/10.1515/bog-2016-0012

Massam, B.H. (2002). Quality of life: public planning and private living. Progress in planning, 58(3), 141-227. https://doi.org/10.1016/S0305-9006(02)00023-5

Meric, G., Gary, G., Richard, F., \& Tara, V. (2002). Competing on creativity: Placing Ontario's cities in North American context.

Merschdorf, H., Michael, E.H., \& Thomas, B. (2020). Modeling Quality of Urban Life Using a Geospatial Approach. Urban Science, 4(1), 118. https://doi.org/10.3390/urbansci4010005

Mittal, S., Chadchan, J., \& Mishra, S. (2020). Review of concepts, tools and indices for the assessment of urban quality of life. Social Indicators Research, 149(1), 187-214. https://doi.org/10.1007/s11205-019-02232-7

Mizgajski, A., Walaszek, M., \& Kaczmarek, T. (2014). Determinants of the quality of life in the communes of the Poznań Agglomeration A quantitative approach. Quaestiones Geographicae, 33(4), 67-80.

Mizgajski, A., Walaszek, M., \& Kaczmarek, T. (2014). Determinants of the quality of life in the communes of the Poznań Agglomeration: A quantitative approach. Quaestiones Geographicae, 33(4), 67-80. https://doi.org/10.2478/quageo-2014-0050

Mostafa, A.M. (2012). Quality of life indicators in value urban areas: Kasr Elnile Street in Cairo. Procedia-Social and Behavioral Sciences, 50, 254-270. https://doi.org/10.1016/j.sbspro.2012.08.032

Najafifar, A., Hoseinzadeh, J., \& Mojaradi-Gilan, H. (2019). Providing a New Approach to Assessing Tourism Suitability in Iran. Case Study: Badareh City, Ilam Province, Zagros Region. GeoJournal of Tourism and Geosites, 26(3), 780-793. https://doi.org/10.30892/gtg.26309-397

Norman, D., \& Olaf, H. (1963). An experimental application of the Delphi method to the use of experts. Management science, 9(3), 458-467. https://doi.org/10.1287/mnsc.9.3.458

Onnom, W., Tripathi, N., Nitivattananon, V., \& Ninsawat, S. (2018). Development of a liveable city index (LCI) using multi criteria geospatial modelling for medium class cities in developing countries. Sustainability, 10(2), 520. https://doi.org/10.3390/su10020520

Ouma, Y., \& Tateishi, R. (2014). Urban flood vulnerability and risk mapping using integrated multi-parametric AHP and GIS: methodological overview and case study assessment. Water, 6(6), 1515-1545. https://doi.org/10.3390/w6061515

Qureshi, M.I., Bhatti, M.N., Rasli, A.M., Yasir, M., \& Zaman, K. (2014). The delphi method for internationalization of higher education in Pakistan: integrating theory of constraints and quality function deployment. Mediterranean Journal of Social Sciences, 5(20), 2702. https://doi.org/10.5901/mjss.2014.v5n20p2702

Raghunath, M. (2006). Application of Remote Sensing and GIS in Urban Land Suitability modeling at Parcel Level Using Multi-Criteria Decision Analysis. Indian Institute of Remote Sensing.

Rinner, C. (2007). A geographic visualization approach to multi-criteria evaluation of urban quality of life. International Journal of Geographical Information Science, 21(8), 907-919. https://doi.org/10.1080/13658810701349060

Rowe, G., \& Wright, G. (2001). Expert opinions in forecasting: the role of the Delphi technique. In Principles of forecasting, 125-144.

Saaty, T. (1990). Decision making for leaders: the analytic hierarchy process for decisions in a complex world. RWS Publications.

Saaty, T.L. (1980). Analytic Heirarchy Process. Wiley StatsRef: Statistics Reference Online.

Saaty, T.L. (2008). Decision making with the analytic hierarchy process. International journal of services sciences, 1(1), 83-98. https://doi.org/10.1504/IJSSci.2008.01759

Sackman, H. (1974). Delphi assessment: Expert opinion, forecasting, and group process. Rand Corp Santa Monica CA.

Shokati, B., \& Feizizadeh, B. (2019). Sensitivity and uncertainty analysis of agro-ecological modeling for saffron plant cultivation using GIS spatial decision-making methods. Journal of Environmental Planning and Management, 62(3), 517-533. https://doi.org/ 10.1080/09640568.2018.1427561

Turoff, M., \& Scher, J. (2002). New Jersey Institute of Technology. The Delphi Method Techniques and Applications. Edited by Harold A. Linstone, Portland State University. With a Foreword by Olaf Helmer, University of Southern California.

Wei, L., Li, H.1., Liu, Q., Chen, J.Y., \& Cui, Y.J. (2011). Study and implementation of fire sites planning based on GIS and AHP. procedia engineering, 11, 486-495. https://doi.org/10.1016/j.proeng.2011.04.687

*** AARP-AARP Public Policy Institute. (2018). AARP livability index - Great neighborhoods for all ages. https ://livab ility index .aarp.org/pdf_repor t

*** NYC-New York City Center for Innovation through Data Intelligence (CIDI) (2015). State of New Yorkers-A well-being index. https ://www1.nyc.gov/asset s/cidi/downl oads/pdfs/nyc_well_being_index_full_repor t_2015.pdf. 